\title{
SILVICULTURE IN THE PRAIRIE PROVINCES
}

\section{BY J. D. B. Harrison}

The Forest Service has attempted at different times during the past to determine the correct silvicultural procedure in various forest types. It has also consulted different outside authorities and obtained their recommendations, but in the majority of cases the advice given, although doubtless sound in itself, has not been possible to put into practice on account of economic conditions. I intend to confine this paper entirely to the work done in connection with practical logging operations. The research programme is another matter. In attempting to give you an idea of the silvicultural work carried on on the National Forests in the Prairie Prov. inces, I shall consider the subject under three heads; first, the objectives aimed at and the difficulties encountered; then a summary of the practical methods used; and finally a consideration of some other phases of the work with which silviculture is closely related.

PROBLEMS AND STUDIES.

Our most valuable tree species are white and black spruce, which supply saw timber and pulpwood, and jack pine which is used for railway ties, poles and mine timber. Jack pine is replaced in parts of Alberta by lodgepole pine. The pines have received relatively little attention, due to the fact that they seem to reproduce easily on their natural sites, and also because there are tremendous areas already stocked with fine young growth, established after fires in the past, which will become progressively available in the future. Black spruce often reproduces well after logging without special provisions for seed supply. White Spruce is our most valuable species and at the same time is the most difficult to reproduce, due in part to its intermittent seed years.

Present stumpage values have made intermediate treatments during the development of stands out of the question, and the same factor rules out artificial re-establishment on a commercial scale. Due to the relation between logging costs and stands per acre such complicated methods as the shelterwood system have not been used. The problem becomes the reproduction of white spruce by natural seeding, without much expenditure at the time of harvesting the mature crop. We are satisfied that such reproduction can be secured, at least for the majority of our sites, but at the same time we are aware that in many cases it will only come in slowly.

Field studiees have been made to ascertain the reasons for the slow reproduction of this species, and it has been clearly shown that the difficulties encountered are in the main due to two causes, namely, seed supply and seed-bed conditions. On the heavier clay soils where spruce has grown in mixed stands the competition of ground cover and more par- 
ticularly of hazel brush has sometimes been a determining factor. The question of seed supply arises from the fact that white spruce only bears good seed crops at intermittent periods of three to six years. Logging operations cannot be confined to seed years, nor can the good seed years be predicted in advance. The question, however, is soluble by the reservation of selected seed trees on the area logged over. The problem of seedbed conditions is much more difficult. Under the mature poplar-spruce stands found in Manitoba and Saskatchewan, the raw humus is generally sour and decomposition is frequently at a standstill. This trouble rapidly corrects itself after the timber is cut. In Alberta deep moss is common under spruce stands. The moss also breaks down after logging but the process is slow. In most of our stands the litter and humus, or moss, form a thick covering over the mineral soil which can be broken up rapidly only by mechanical means or by fire. Special mechanical means such as the Swedish plough have proved impracticable, and the use of broadcast fire at the time it would do most good, that is, in the autumn, is so far considered too dangerous; besides, the cost of protecting the seed trees from a broadcast burn is excessive. Certain disturbance of the top soil accompanies logging operations and on this we must depend for the present.

While our main problem is the natural reproduction of spruce, the day will come when artificial reproduction will be needed for some areas. With this in mind small nurseries are being developed on the forests, with an eye to later expansion. These nurseries are on the whole doing well and some of them could be expanded at short notice. Stock supplied on the ground will greatly reduce planting costs and cheap experimental plantings have already been made.

\section{PRACTICAL METHODS.}

Logging operations on the National Forests are carried on subject to certain conditions which include the utilization of small tops, cutting low stumps, and disposal of coniferous slash by burning in small piles as the operation progresses. Sales of timber have varied in size from 100,000 f.b.m. to almost 20 million f.b.m.

A general regulation requiring operators to cut only such timber as is designed for removal by the forest officer in charge of the sale provides our basis for the practice of silviculture; perhaps more properly our attempts at silviculture.

Much spruce saw timber has been cut in the Prairie Provinces under a "blanket" diameter limit regulation. Now the "diameter limit" can of itself be useful, provided that it is applied to stands of the right kind, and provided that the limit is intelligently selected for each stand. In a true selection forest it may work fairly well, at least as a preliminary sil- 
vicultural measure, and in a distinctly two storied stand where it is desirable to remove all the upper story it is satisfactory; but where the stands to which a low "blanket" limit is applied are mature or overmature, where the trees of the smaller diameters are merely more or less severely suppressed specimens of nearly the same age as the larger trees, the method is disastrous. Unfortunately these last conditions have been fulfilled to the letter on many of the spruce saw timber areas logged in these provinces. The worst feature of the method is that it leaves over-topped or suppressed trees as the sole seed supply. Such trees frequently do not bear seed. In cases where a comparatively large number of trees per acre are left there may still be no adequate supply of seed. To quote a particular case; on a cutover timber berth where a $10^{\prime \prime}$ stump diameter was used, an examination of seed supply was made in the early autumn of an exceptionally good seed year. Dominant spruce on an adjoining uncut area were heavily loaded with cones. On the cutover area there were 34 spruce per acre still standing (three years after logging) most of which were under $10^{\prime \prime}$ d.b.h. and all of which had compressed or damaged crowns. Of these 34 trees, 21 bore no seed whatever; of the 13 trees with cones, four had a few small clusters, and the remaining nine only scattered single cones. Of course the total supply of seed per acre was only a fraction of the amount borne by a single dominant tree on the uncut area.

In an effort to get away from the disadvantages of the diameter limit, the Forest Service commenced marking all trees to be cut. In practice the forester reporting on a proposed sale recommended that the area should be cut to a selected "flexible" diameter limit. It was intended that the limit set should be used as a guide only, and that the marker should spot defective but still merchantable trees below the limit for removal and where necessary leave trees above the limit unmarked, as seed trees. Due to the shortage of technically trained men most of the actual marking was done by the forest rangers, after some instruction by a forester. This method was expected to give good results. After it had been in force for some years careful examinations were made of a number of sale areas. Further examinations were made of areas cut over under diameter limits. Comparative data was secured on reproduction, residual stands, and so on. The results of the marking were disappointing. In many cases the results showed little improvement over the old method; hence it followed that the time, work and money spent on selective marking were practically lost. The main reasons of failure in the cases examined were as follows:

1. Many of the stands marked were overmature and even aged, and not of the selective forest form; or in other words, selection cutting was the wrong method. 
2. The men who did the actual marking were not sufficiently trained. The work is much more difficult than was at first supposed, as it involves keeping a mental picture of the whole stand constantly in the mind's eye. It was almost impossible to convince men that a maximum number of trees marked per day was not the objective. Rangers are usually busy men, and marking was consequently done with too much haste.

3. Where single trees were left unmarked, as seed trees, they were frequently cut, the sawyers claiming that they thought these good trees had been merely overlooked by the markers. This detail is hard to check and disciplining the operator does not restore the lost seed supply.

A further objection to selective marking on many timber sales under present conditions lies in the time consumed by the work. This is an important item in saw log operations, and becomes practically prohibitive on a pulpwood cut.

It should be clearly understood that this is no general condemnation of selective marking, but rather a demonstration of its drawbacks under our present conditions in the woods and with our present staffs. It is now used mainly for designating trees to be cut on such small operations as settlers' permits, and of course in cases where the forest is of true selective form. In future, as second growth forests develop, and as sufficiently trained silviculturists become available, it will of course become a standard practice.

The silvicultural method mainly used during the past few years has been that of marking certain trees to be left rather than those to be cut. This method has proved to have many advantages from the administrative point of view and is expected to give the best success possible with the limited expenditures so far permissible for the practical silviculture. It is unfortunate that as yet we have no conclusive studies of results; nevertheless some work has been done which reinforces general observation.

The forester reporting on a proposed sale area recommends the number of seed trees per acre which should be left and specifies the size limits between which they should liz; frequently these limits call for free trees of from 11" to $14^{\prime \prime}$ d.b.h. The interval between seed trees is calculated, and the marker is advised accordingly. $\mathrm{He}$ is instructed to mark suitable trees spaced at the given interval, such trees to have free crowns, conical tops, well-buttressed roots and no signs of infestation or disease. The actual work is done by running compass lines back and forth across the area and spotting trees at the required distances. The best mark seems to be four small bark blazes, one at each side of the tree, and at breast height. Unnecessary damage to the cambium must be avoided and with smooth barked trees a mere scrape with the face of the axe is a sufficient mark. The simplicity of the field work is apparent. Further, there is no difficulty 
in training any reasonably good woodsman to do the work and to do it well. The "tree interval" can be varied for different parts of the area according to local variations of stand.

The number of seed trees left may vary considerably; sometimes as low as four trees per acre is sufficient. Studies have been made of the distance trees may be expected to seed, and observations on wind loss have also been made. In general the danger of losing seed trees through wind damage is not as great as was anticipated, always providing that the trees are carefully selected. In one case where seed trees were marked over 50 acres only one tree was down at the end of the first summer after logging and that was broken by loggers. Our wind losses of all species in residual stands of the spruce-poplar type tend to a maximum of $25 \%-30 \%$, ten to twelve years after logging. Thus the reservation of seed trees gives good assurance that seed supply will be provided.

With fairly definite lower limits of merchantability, and with the presence of unmerchantable species in our stands, we seldom get clear cuts, even where leaving marked trees is the only condition insisted on. A sort of "economic diameter limit" ensures that some small diameter spruce will be left. Sometimes conditions of stand are such that a designated diameter limit can be used, together with marked seed trees, to obtain a second cut from a given area in less than a full rotation. This combination is very useful. The method can also be extended to marking all trees to be left, under certain circumstances where a second cut is expected.

To summarize: the seed tree method in most cases ensures an adequate seed supply for a considerable period in the future. Reproduction in a few cases is quick and good; in others it is slow, but in the long run is fairly sure. Great alterations take place in top soil conditions after the admission of light and air by logging. In some cases conditions may become favourable for spruce reproduction some time after logging; and if they do become favourable, the seed is there.

The practical advantages of the method are:

1. The feasibility of training personnel to do the marking properly.

2. The ease and speed of the actual work.

3. The ease of checking up on the cutting, since trees are left at approximately regular intervals.

The fact that in most cases seed trees left cannot be harvested later, and therefore constitute a sacrifice of material, is inevitable. This loss must be considered as an investment in futures.

\section{GENERAL CONSIDERATIONS.}

One of the most definite conclusions which our past experience in dicates, is that practical silviculture can only be properly considered in connection with other phases of the work. After all, the words "practical 
silviculture" are entirely without meaning unless the vital question of costs is taken into consideration. Such matters as slash disposal, utilization and the need for working plans have an especially close connection with our subject.

Considerable assistance to reproduction was expected from the practice of slash burning, and for the spruce and spruce-poplar types this expectation seems to have been well founded. Studies in the mature spruce-poplar type (which bore from 4 to $10 \mathrm{M}$. f.b.m. per acre) show that the number of "burned spots" which have cleared mineral soil is only about 11 per acre. Reproduction is certainly good in these spots, though sometimes delayed for a few years by a special kind of moss; but as only one tree can eventually develop in one spot the effect on the final crop cannot be great. Many brush fires only burn part way through the humus and leave cup-shaped depressions filled with wood ash in which reproduction does not take place, at least for some time. However, where the layer of vegetable soil happens to be thin the area of mineral soil exposed is undoubtedly greater.

The majority of small growth coming in during the years immediately after logging establishes itself on portions of the ground surface which have been disturbed by skidding teams. Where slash is burned the course of skidding teams is not pre-determined by the presence of large piles and windrows of brush and consequently more of the surface is actually disturbed. Further, where slash is left it covers a considerable percentage of the ground surface-sometimes as high as $20 \%$. Spruce will not regenerate under brush piles, and it takes from ten to fifteen years for spruce slash to rot away; so that the release of area open to reproduction is alone a strong silvicultural argument for slash disposal. Thus the greatest benefits to reproduction from slash disposal may not lie in the preparation of seed spots by fires.

Questions of utilization and operating costs are closely bound up with silvicultural measures, and I would not hesitate to say that intelligent consideration of future developments in practical silviculture is not possible without access to reliable data on logging costs and market prices. For example, such information alone can indicate the feasibility of removing several small cuts from an area at short intervals. A question of importance in determining what we may or may not reasonably do in a silvicultural way is: "What size classes of trees are truly merchantable for a given purpose?" The importance of such information was clearly indicated a few seasons ago when a lumber company applied for an exceptionally large timber sale. The wood in question was overmature for the most part and was not accessible to any other company. The Service decided to have this material cut to a 12 " b.h. diameter limit, with the usual requirement of utilization to a $6^{\prime \prime}$ top. The company urgently re, 
quested that they be allowed to cut down to $10^{\prime \prime}$ d.b.h. Permission was granted. Operations covered a space of three years. At the end of the second year the company applied for permission to leave all logs under $8^{\prime \prime}$ top diameter in the woods, and even offered to pay stumpage on the $6^{\prime \prime}$ and $7 "$ "tops so left. They stated that they were getting too high a percentage of small logs to allow them to operate their mill at a profit. A careful study was undertaken, log scales and stand tables were analyzed and it was definitely shown that the excess of small logs complained of almost exactly corresponded to the number of logs from the $10^{\prime \prime}$ and $11^{\prime \prime}$ trees, which the company had asked for permission to cut. In this case through lack of sound cost data the company had loaded themselves with an unnecessary burden and at the same time the Service consented to a reduction in cutting regulations which left this particular stand in poorer shape from the silvicultural point of view than it need have been. In other words, both parties to the bargain lost. The conclusions are obvious.

The other requisite to wise silvicultural procedure is a working plannot necessarily carried out to the last degree of precision, but one which will at least allot lands to definite purposes, and show the inter-relation between stands. It has been found very difficult for a forester to formulate the correct measures to be taken in a given stand (which may happen to constitute a proposed cutting area at the moment) without knowledge of adjoining stands of timber and of the ultimate use of the land. To achieve an objective one must first define it.

CONCLUSIONS.

In closing I would like to draw a few conclusions for your consideration.

1. That advances in practical silviculture must be based in part on the accumulation of accurate cost data.

2. That sound development in silviculture must follow, and can hardly precede, the formulation of some sort of management plans.

3. That good silviculture requires adequate personnel. It is useless to hope to develop good silviculture in any given region without developing a staff whose main interest and responsibility lies in the production of forest crops; and who have ample opportunities to gain experience in the particular problems of their own district. 